\title{
Physically based retrieval of crop characteristics for improved water use estimates
}

\author{
K. Richter ${ }^{1}$ and W. J. Timmermans ${ }^{2}$ \\ ${ }^{1}$ Department of Agricultural Engineering, University of Naples "Federico II", via Università 100, 80055 Portici (Na), Italy \\ ${ }^{2}$ International Institute for Geo-information Sciences and Earth Observation, Dept. of Water Resources, P. O. Box 6, \\ 7500 AA Enschede, The Netherlands
}

Received: 28 January 2009 - Published in Hydrol. Earth Syst. Sci. Discuss.: 6 March 2009

Revised: 20 May 2009 - Accepted: 21 May 2009 - Published: 27 May 2009

\begin{abstract}
The increasing scarcity of water from local to global scales requires the efficient monitoring of this valuable resource, especially in the context of a sustainable management in irrigated agriculture. In this study, a two-source energy balance model (TSEB) was applied to the Barrax test site. The inputs of leaf area index (LAI) and fractional vegetation cover (fCover) were estimated from CHRIS imagery by using the traditional scaled NDVI and a look-up table (LUT) inversion approach. The LUT was constructed by using the well established SAILH + PROSPECT radiative transfer model. Simulated fluxes were compared with tower measurements and vegetation characteristics were evaluated with in situ LAI and fCover measurements of a range of crops from the SPARC campaign 2004. Results showed a better retrieval performance for the LUT approach for canopy parameters, affecting flux predictions that were related to land use.
\end{abstract}

\section{Introduction}

Given the increasing scarcity of water at local, regional and global scales, an efficient monitoring of this valuable resource becomes more and more essential, especially in the context of a sustainable management in irrigated agriculture and other water-related disciplines, such as hydrological modelling, numerical weather forecasting or climate change prediction (Anderson et al., 2007). Partitioning of available energy between sensible and latent heat is hereby of prime interest and various models have been developed in the

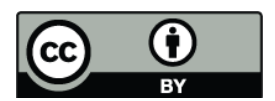

Correspondence to: K. Richter (katja.rich@gmail.com) last years that describe this interaction between land surface and atmosphere. Those models, known as soil-vegetationatmosphere transfer schemes (SVAT), vary widely in their complexity and dimensionality (Timmermans et al., 2007).

The conjunction of currently optical, thermal and microwave Earth Observation (E. O.) data with SVAT schemes allows the spatial estimation of surface flux partitioning from land-surface temperature and dynamic vegetation variables (Anderson et al., 2007; Bindlish et al., 2001; Schmugge et al., 1998). For homogeneous canopies and land surfaces, a single-source modelling approach can be sufficient. However, vegetated surfaces are usually under heterogeneous conditions, which are better described by two-source models, treating the land surface as a composite of soil and vegetation components with separate fluxes and temperatures (Anderson et al., 2007; Timmermans et al., 2007). The TwoSource Energy Balance model (TSEB) for instance, first described in Norman et al. (1995) and updated by Kustas and Norman (1999) and Kustas et al. (2004), uses directional radiometric surface temperature for estimating component heat fluxes from soil and vegetation, i.e. instantaneous fluxes of net radiation $\left(R_{N}\right)$, soil $(G)$, sensible $(H)$ and latent heat $(L E)$. Several studies validated TSEB successfully against flux tower measurements or other modelling schemes (e.g. Anderson et al., 2007; Schmugge et al., 1998; Timmermans et al., 2007) and research is ongoing to improve model performance (Kustas and Norman, 1999; Li et al., 2005). Innumerable publications focused on improving accuracy of temperature and roughness characteristics, but despite the importance of vegetation characteristics, still either rather simple empirical models are used, or vegetation parameters are derived from visual observations, some samples or indirectly from measurements of biomass or plant species type (Zhan et al., 1996). However, analyses by Zhan et al. (1996) and

Published by Copernicus Publications on behalf of the European Geosciences Union. 
more recently by Timmermans et al. (2007) revealed that TSEB, as well as other existing models, shows a considerable sensitivity to small variations of fractional vegetation cover (fCover) and/or leaf area index (LAI) on soil and canopy temperature estimation, in particular for high cover conditions. These findings emphasize the importance of accurate values of these parameters, usually determined from optical E. O. data. Although not model specific, the common approach applied within the TSEB model to estimate LAI and fCover is by means of rather simple empirical formulations utilizing either the Normalized Difference Vegetation Index (NDVI) (Schmugge et al., 1998) or a scaled NDVI (Choudhury et al., 1994; French et al., 2003; Kustas and Norman, 1999). Such empirical approaches are based on relationships between the parameter (e.g. LAI) and Vegetation Indices (VIs). Many studies showed that the application of VIs can give appropriate results, especially when using newly developed hyperspectral VIs (e.g. Haboudane et al., 2004). However, a spectral signature is the integration of several factors and can not be explained by just one parameter. Moreover, these empirical models are often crop-, site- and sensor-specific (Atzberger, 2004; Vuolo et al., 2008). Therefore, many efforts have been undertaken in the last decades to develop and improve canopy reflectance models based on radiative transfer equations. In these radiative transfer models (RTM), the complexity of the spectral signal is taken into account by a function of canopy geometry (e.g. LAI, leaf angle distribution), optical leaf and soil properties, illumination and viewing geometry. Inversion of such models then offers the possibility of extracting these biophysical parameters.

The objective of the present study is to test whether a physically based retrieval of LAI and fCover can support more accurate estimations of fluxes in two-source energy balance modelling.

\section{Material and methods}

In this section first a description of the models used for the estimation of vegetation characteristics and energy fluxes is given. Then the campaign with ground and E. O. data acquisitions is described.

\subsection{Estimation of vegetation characteristics}

\subsubsection{Empirical model}

Traditionally, the estimation of surface parameters for energy balance modelling is based on empirical methods. Several empirical models have been developed to estimate the biophysical parameters. Though not characteristic for the TSEB model, recent versions (French et al., 2003; Li et al., 2005) employ the approach as proposed by Choudhury et al. (1994). This so-called scaled NDVI - approach deter- mines fCover for nadir viewing angles (fCover $\left(\theta_{o}\right), \theta_{o}=0$ ) as follows:

fCover $(0)=1-\left(\frac{\mathrm{NDVI}_{\max }-\mathrm{NDVI}}{\mathrm{NDVI}_{\max }-\mathrm{NDVI}_{\min }}\right)^{p}$

Hereby, the end-member NDVI values, $\mathrm{NDVI}_{\max }$ and $\mathrm{NDVI}_{\text {min }}$, characterize a surface fully covered and completely uncovered by vegetation, respectively. The parameter $p$ is defined as $p=\Lambda / \kappa$, describing the ratio of a leaf angle distribution term, $\Lambda$ (set to 0.5 for randomly oriented leaves, Campbell and Norman, 1998), to canopy extinction, $\kappa$ (set to 0.55 , approximating typical extinction for many canopies at a solar zenith angle of 25 degrees, following Campbell and Norman, 1998), leading to a $p$ value of 0.9 .

The NDVI end-members were obtained by combining an NDVI histogram analysis (Timmermans et al., 2007) with local field observations resulting in $\mathrm{NDVI}_{\max }=0.85$ and $\mathrm{NDVI}_{\min }=0.10$.

Leaf area index (LAI), is then calculated from fCover (Choudhury, 1987):

$\mathrm{LAI}=\frac{\ln (1-\mathrm{fCover}(0))}{\Lambda}$

\subsubsection{Radiative transfer model}

As an alternative to the empirical approach, a physically based model of canopy reflectance was applied: the combined SAILH (Kuusk, 1991; Verhoef, 1984, 1985) and PROSPECT (Jacquemoud and Baret, 1990) models (called "PROSAILH"), widely used for canopy reflectance modelling and applications, amongst others by Atzberger (2004), Baret et al. (2007), Darvishzadeh et al. (2008), Richter et al. (2009) or Weiss et al. (2000).

SAILH is a one-dimensional turbid medium radiative transfer model, later modified to take into account the hot spot effect (Kuusk, 1991). It simulates the bidirectional topof-canopy (TOC) reflectance as a function of three structure parameters, defined by LAI $\left(\mathrm{m}^{2} / \mathrm{m}^{2}\right)$; average leaf inclination angle, ALA (deg), assuming an ellipsoidal distribution, and hot spot size parameter, Hot $(\mathrm{m} / \mathrm{m})$. Further it requires the soil spectral reflectance, fraction of diffuse incoming solar radiation $(s k y l)$, and the view and illumination geometry (i.e. sun zenith angle, $\theta_{s}(\mathrm{deg})$; sensor viewing angle, $\theta_{o}$ (deg) and azimuth angle between sun and sensor, $\phi(\mathrm{deg})$ ). Leaf hemispherical reflectance and transmittance are simulated by the PROSPECT model as a function of four structural and biochemical parameters: leaf chlorophyll $\mathrm{a}+\mathrm{b}$ concentration, $C_{a b}\left(\mu \mathrm{g} / \mathrm{cm}^{2}\right)$; dry matter content, $C_{m}\left(\mathrm{mg} / \mathrm{cm}^{2}\right)$; leaf water thickness, $C_{w}(\mathrm{~cm})$ and a leaf mesophyll structural parameter, $N$ (unitless). To account for the changes in soil reflectance (induced by soil water content and roughness), a wavelength independent scaling factor " $\alpha_{\text {soil }}$ " is introduced, i.e. multiplied with the soil spectrum. 
Table 1. Ranges of the input variables for PROSAILH to generate the LUT database.

\begin{tabular}{lllll}
\hline Model Variables & & Units & Min (LB) & Max (UB) \\
\hline $\begin{array}{l}\text { Leaf parameters: } \\
\text { (PROSPECT) }\end{array}$ & & & & \\
$N^{\mathrm{a}}$ & Leaf structure index & unitless & 1.3 & 1.7 \\
$C_{a b}^{\mathrm{b}}$ & Leaf chlorophyll content & {$\left[\mu \mathrm{g} / \mathrm{cm}^{2}\right]$} & 20 & 70 \\
$C_{m}^{\mathrm{b}}$ & Leaf dry matter content & {$\left[\mathrm{g} / \mathrm{cm}^{2}\right]$} & 0.004 & 0.01 \\
Canopy variables: & & & & \\
$(\mathrm{SAILH})$ & & & & \\
LAI & Leaf area index & {$\left[\mathrm{m}^{2} / \mathrm{m}^{2}\right]$} & 0 & 6.0 \\
ALA & Average leaf angle & {$\left[{ }^{0}\right]$} & 40 & 60 \\
HotS $^{\mathrm{d}}$ & Hot spot parameter & {$[\mathrm{m} / \mathrm{m}]$} & 0.01 & 1 \\
$\alpha_{\text {soil }}^{\mathrm{e}}$ & Soil reflectance factor & unitless & 0.6 & 1.4 \\
\hline
\end{tabular}

a not measurable, therefore range set in order to comprise values often used in literature (e.g. by Weiss et al., 2000);

b (somewhat extended) range of measurements (SPARC report 2004);

c ALA - mean of MTA (measured with LAI-2000 instrument) \pm standard deviation, sd (mean: 50, sd: 11) (SPARC report 2004);

d similar to range often used in literature (e.g. Baret et al., 2007; Vuolo et al., 2008);

$\mathrm{e}$ distribution of the factor observed over a number of bare soil pixels from the CHRIS imagery.

When calculating reflectance, the SAILH model estimates the gap fraction, which is a key variable driving light interception by the canopy. Gap fraction is defined as the probability of a ray of light passing through the canopy without encountering foliage or other plant elements, and is consequently the complement of fCover. The gap fraction, calculated by SAILH corresponds therefore to 1 -fCover.

In order to estimate LAI and/or the other parameters, the PROSAILH model must be inverted. In this study a fast lookup table (LUT) approach (e.g. Darvishzadeh et al., 2008; Richter et al., 2009; Weiss et al., 2000) has been chosen, offering a good alternative to other inversion procedures such as artificial neural networks (NN) (Atzberger, 2004) or numerical optimization methods (Vuolo et al., 2008), amongst others for the following reasons: first, the LUT technique permits a global search and avoids therefore the trapping into local minima as occurs with the optimisation methods (Darvishzadeh et al., 2008). Second, it shows less unexpected behaviour than $\mathrm{NN}$ when the spectral signal of the surface is not well simulated by the model (for a discussion of different inversion methods see Atzberger, 2004; Darvishzadeh et al., 2008; or Richter et al., 2009).

PROSAILH was selected since it presents a good compromise between physical complexity and computation time requirements and has been therefore preferred over (perhaps more accurate) models with complex parameterization schemes.

\subsubsection{RTM models setup}

The LUT is established in advance of the model inversion process. For this purpose PROSAILH is run to simulate bidirectional canopy reflectance and fCover for a number of
100000 parameter combinations. This size was regarded by Weiss et al. (2000) as a good compromise between computer resources requirements and the accuracy of the estimates. The LUT was established by randomly sampling all parameters within their bounds. In this way, all combinations of parameters were covered, but no adaptations to possible sensitivities of the parameters were implemented.

The range of canopy characteristics was described by taking partly into account a priori information from the campaigns measurements. The usage of on-site measurement information is one possibility to regulate the ill-posed inverse problem, which is pronounced between LAI and ALA, and therefore to improve the parameter (LAI) retrievals (Atzberger, 2004; Combal et al., 2003) (Sect. 2.3.3, SPARC report, 2004). The information about all parameter ranges can be found in Table 1 .

Distributions of all parameters were uniform, so that no emphasis was placed on higher or larger values. Illumination and view conditions were set according to the conditions during the overpass: $\theta_{s}=21^{\circ}, \theta_{o}=8.4^{\circ}$ and $\phi=138^{\circ}$. The parameter skyl was set to 0.1 across all wavebands, according to similar studies (e.g. Richter et al., 2009).

As the absorption of leaf water is not influencing the spectral range used in this study $(<0.9 \mu \mathrm{m}), C_{w}$ was fixed to an arbitrary value $\left(C_{w}=0.02 \mathrm{~cm}\right)$.

Only a limited number of bands is necessary to describe and differentiate the influence of canopy and soil parameters on the spectrum (Weiss et al., 2000). Consequently, in order to minimize redundancy of spectral data and to speed up the calculation process of the LUT, a spectral sampling of only 8 bands has been selected. It is based on the future ESA satellite Sentinel-2, developed in the 
framework of Global Monitoring for Environment and Security (GMES/Kopernikus, ESA, 2007) to replace and improve the old generation of satellite sensors. Sentinel-2 is scheduled to be launched in the year 2012 and as outcome the mission will provide service data, comprising products such as LAI and fCover. The multi spectral data, used for the simulations in the study, involve the following CHRIS wavebands: $492,563,664,706,738,773,844$ and $862 \mathrm{~nm}$ (corresponding to Sentinel-2: 490, 560, 665, 705, 740, 775, 842 and $865 \mathrm{~nm}$, ESA 2007). In this way all spectral bands of Sentinel-2 with the purpose to retrieve LAI and other vegetation characteristics (i.e. 8 out of 13 bands) are included. This spectral sampling has been tested for its suitability for LAI estimation by Richter et al. (2009).

In the final step the solution within the LUT is selected by applying a simple cost function calculating the root mean square error (RMSE) between simulated and measured spectra (e.g. Darvishzadeh et al., 2008), as follows:

$\mathrm{RMSE}=\sqrt{\frac{\sum_{i=1}^{n} R_{\operatorname{meas}(\lambda)}-R_{\operatorname{lut}(\lambda))^{2}}}{n}}$

where $R_{\text {meas }}$ corresponds to the measured reflectance at wavelength $\lambda$, and $R_{\text {lut }}$ stands for the simulated reflectance calculated with the PROSAILH model. The number of bands is indicated with $n$.

The resulting parameter combination was built as the average of all parameter combinations found within less than $20 \%$ of the lowest RMSE value (e.g. Richter et al., 2009).

\subsection{TSEB model}

The land surface model used here to derive latent and sensible heat fluxes is originally designed to use input data primarily from remote sensing platforms. Its main characteristic is that it discriminates between a soil and vegetation component, aiming at a more physical description of heterogeneous surfaces when dealing with radiative and aerodynamic properties. Required remote sensing input consists of spatial information on surface temperature as well as vegetation density, being fCover and LAI. The version implemented here basically follows what is described as the "series resistance network" in Appendix A of Norman et al. (1995). In the current version a physically based algorithm is implemented for estimating the net radiation, which is described in detail in Kustas and Norman (1999). As such, the model implemented is described in detail in Norman et al. (1995) and Kustas and Norman (1999); reason to only sketch its main characteristics and highlight those parts that are affected by fCover and LAI.

First of all, fCover is used to estimate canopy and soil temperatures ( $T_{C}$ and $T_{S}$, respectively) from observed radiometric surface temperature, $T_{R}$, with a simple non-linear mixing model, described by:

$T_{R}^{n}=$ fCover $_{T_{C}^{n}}+(1-$ fCover $) T_{S}^{n}$. where $n$ is the power in the Stefan-Boltzmann equation that reasonably approximates the appropriate integral of the Planck blackbody emission function for the wavelength of the sensor.

A first estimate of the latent heat flux from the canopy, $L E_{C}$, is obtained by applying the Priestley and Taylor approach on the canopy component of the net radiation, $R_{N, C}$, which works reasonably well under unstressed vegetation conditions. The canopy sensible heat flux, $H_{C}$, is then determined by evaluating the canopy energy budget. By using a linearized form of Eq. (4), following the procedure outlined in the Appendix A of Norman et al. (1995), the withincanopy air temperature, $T_{A C}$, is derived, which also yields the canopy temperature, $T_{C}$. Substitution in Eq. (4) yields $T_{S}$, providing the possibility of obtaining the soil sensible heat flux, $H_{S}$. The soil heat flux, $G$, is determined as a timedependant ratio of the soil net radiation, $R_{N, S}$, after which the soil latent heat flux, $L E_{S}$, is determined by evaluating the soil energy budget. In case $L E_{S}$ is negative, then the soil is likely to be dry and $L E_{S}$ is set to zero. Under these circumstances, $H_{S}$ is derived from the soil energy budget, and an adjusted $T_{S}$ is obtained. Equation (4) provides a new estimate for $T_{C}$ which is then used to calculate an updated $H_{C}$.

The algorithm used for estimating the net radiation divergence requires incident solar radiation observations and formulations for the transmission of direct and diffuse shortwave radiation and for the transmission of longwave radiation through the canopy (Campbell and Norman, 1998). The canopy component of net radiation, $R_{N, C}$, is given by:

$$
\begin{aligned}
R_{N, C} & =\left(1-\tau_{L W}\right) \times\left(R_{L W, \text { sky }}+R_{L W, S}-2 R_{L W, C}\right) \\
& +\left(1-\tau_{S W}\right) \times\left(1-\rho_{C}\right) \times R_{S W}
\end{aligned}
$$

and the soil net radiation component, $R_{N, S}$, by:

$$
\begin{aligned}
R_{N, S} & =\tau_{L W} \times R_{L W, \mathrm{sky}}+\left(1-\tau_{L W}\right) \times R_{L W, C} \\
& -R_{L W, S}+\tau_{S W} \times\left(1-\rho_{S}\right) \times R_{S W}
\end{aligned}
$$

where $\tau$ represents transmissivity through the canopy and subscripts $S W$ and $L W$ stand for shortwave and longwave, respectively. Subscripts sky, $S$ and $C$ represent the sky, soil and canopy components, whereas $\rho$ is the reflectance, or shortwave albedo. Since the reflection and absorption of radiation in the visible and near-infrared wavelengths are rather different for vegetation and soils, the visible and near-infrared albedos of the soil and canopy were evaluated differently before combining to give an overall shortwave albedo. The equations for estimating the transmission and reflection of direct and diffuse shortwave radiation are provided in Campbell and Norman (1998). We suffice here with the observation that their spatial variation is solely determined by LAI. The longwave transmissivity finally is approximated by a single exponential function depending on an extinction coefficient and LAI. 
The parameterization of the resistances used in the series resistance network was taken from Norman et al. (1995). Aerodynamic properties such as canopy height, displacement height, aerodynamic roughness, leaf width, as well as limited micrometeorological observations are required as input parameters and are assigned a priori. They are described in the following section.

\subsection{Experimental setup and observations}

\subsubsection{Site description}

The analyses are based on data of the interdisciplinary ESA SPARC 2004 Campaign. (Moreno et al., 2004; SPARC report 2004). The objective of the campaign was to advance the understanding of land - atmosphere exchanges of water and energy in space and time over heterogeneous land surfaces.

In this context, satellite and ground data were collected in Barrax $\left(30^{\circ} 3^{\prime} \mathrm{N}, 2^{\circ} 6^{\prime} \mathrm{W}\right)$, an agricultural test area situated in the Castilla-La Mancha region in southern Spain. Figure 1 shows an overview of the location and the area of interest.

The Barrax site, a flat area at $700 \mathrm{~m}$ above sea level, is characterized by a large variety of uniform land use units of different crops and dry bare soils, leading to a wide range of LAI from 0 up to 6.5 .

The Castilla-La Mancha region receives an annual precipitation of only $400 \mathrm{~mm}$ and is therefore one of the driest regions in Europe. One third of the land is irrigated (35\%), comprising amongst others alfalfa, maize, potatoes, sunflower, onion, garlic, sugar beet and vineyard. The other two thirds $(65 \%)$ are rainfed cultivations, such as winter/spring cereals and bare soils/fallow land.

\subsubsection{E. O. data acquisition}

\section{Optical data}

Hyperspectral and multiangular E. O. data from Compact High Resolution Imaging Spectrometer (CHRIS) instrument, located on the Project for On-Board Autonomy (PROBA) platform, were acquired on 16 July 2004 around 11:25 UTC. Since the system PROBA/CHRIS has multiangular capabilities, five consecutive images from five different view angles have been obtained during the overpass, with a minimum satellite zenith angle of $8.4^{\circ}$. Since it was not the scope of the current study to analyze the contribution of directional information to the parameter estimates (Vuolo et al., 2008), only the imagery with the viewing angle closest to nadir has been considered.

The sensor covers the visible/near-infrared region (from $400 \mathrm{~nm}$ to $1050 \mathrm{~nm}$ ) with a spectral sampling interval ranging between $1.25 \mathrm{~nm}$ (at $400 \mathrm{~nm}$ ) and $11 \mathrm{~nm}$ (at $1000 \mathrm{~nm}$ ). CHRIS data were acquired in Mode-1, having a spatial resolution of $34 \mathrm{~m}$ and 62 spectral bands.

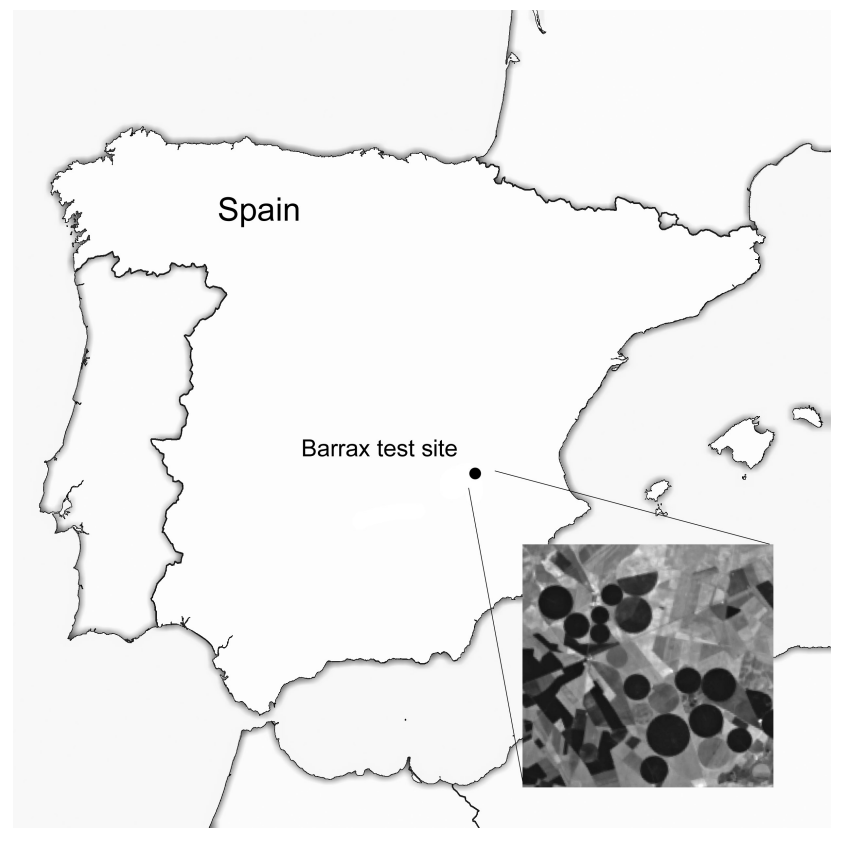

Fig. 1. Location of the study area: Barrax Site, La-Mancha, Spain.

Radiometric calibration and atmospheric and geometric correction of CHRIS imagery were carried out by the Department of Thermodynamics of the University of Valencia.

\section{Thermal imagery}

The thermal remote sensing data from SPARC 2004 used in this study consisted of ASTER imagery, acquired on 18 July 2004 to obtain surface temperature. ASTER has 5 thermal infrared bands with a $90 \mathrm{~m}$ spatial resolution.

After atmospheric correction, the land surface temperature was extracted using a split-window technique (JimenezMunoz and Sobrino, 2007) on channels 13 and 14 of the ASTER data. This method was preferred over the standard TES algorithm due to insufficient accuracy in land surface temperature retrieval that was noted over certain land cover types (Sobrino et al., 2007).

Despite ASTER's excellent capabilities for surface energy flux mapping here CHRIS/PROBA data were used due to their more advantageous spectral characteristics for mapping the vegetation characteristics, assuming these do not change significantly within 2 days time.

\subsubsection{Ground observations}

The ground-based data used here consisted of vegetation characteristics, meteorological observations as well as radiation and turbulent flux exchanges (Su et al., 2008), collected during the time of the satellite acquisitions.

Observations of vegetation surface parameters, such as vegetation height, LAI, mean tilt angle (MTA), fCover, leaf chlorophyll, water and dry matter content, were conducted 
(Fernandez et al., 2005) at several locations for calibration and validation of remote sensing derived vegetation input to the flux model.

Non-destructive field measurements of LAI were performed with the Plant Canopy Analyzer LAI-2000 instrument (LICOR Inc., Lincoln, NE, USA), measuring simultaneously the MTA that corresponds to the ALA parameter in the PROSAILH model (Sect. 2.1.2).

To reduce the effect of multiple scattering on LAI-2000 measurements, the instrument was operated maximal two hours after sunrise or before sunset, under diffuse radiation conditions. In order to prevent interference caused by the operator's presence and the illumination condition, the sensor field of view was limited with a $180^{\circ}$ view-cap. Measurements were azimuthally oriented opposite to the sun azimuth angle. Each single LAI value was the result of an average of 24 measurements taken randomly within an Elementary Sampling Unit (ESU) of approximately $15 \times 15 \mathrm{~m}^{2}$.

Since no corrections were applied to account for clumping or the influence of non-photosynthetic plant components (such as stems), the term "LAI" should here be understood as "effective plant area index" (PAI ${ }_{\text {eff }}$ ) (Chen et al., 1997; Darvishzadeh et al., 2008). However, LAI measured by LAI2000 (or other optical methods) is quite close to the leaf surface visible by a remote sensor which is not necessarily the case for the real LAI. Therefore, a correction for the clumping effect is not absolutely necessary (Stenberg et al., 2004).

A data set of 48 LAI measurements, located in/near the area of interest (maize: 8, garlic: 13, potatoes: 15, sugar beet: 6 , sunflower: 6 ) have been selected for the validation.

Measurements of fCover, being of essential interest for this study, have been performed using hemispherical photography. According to the crop structure, different sampling strategies were applied. The photographs were processed using a specialized software package (CAN-EYE), developed at INRA-CSE Avignon. The procedure of the software is based on gap fraction estimation using classification techniques (detailed information about the measurements and data elaboration can be found in the SPARC 2004 report). The final fCover estimate for each ESU $(20 \times 20 \mathrm{~m})$ was calculated as the average of twelve measurements. For the present study, a total number of 21 measurements have been used for validation (garlic: 4, potatoes: 4 , sunflower: 4 , onion: 4 , sugar beet: 3 , maize: 2 ).

Meteorological and radiation observations (incoming shortwave radiation, air temperature, relative humidity, air pressure and wind speed) that were needed as input to the TSEB model, were taken from a tower in the centre of the area.

Validation data concerning turbulent fluxes exchanges and radiation for the time of the ASTER overpass were made at several locations that were chosen such that typical land cover units were covered (described in detail in Su et al., 2008). They comprised a forest nursery, a wheat stubble field, vineyard ( 2 sites), a sunflower field and a corn field. At all sites measurements of sensible heat flux, $H$, were made either by 1-D or 3-D sonic anemometers or by scintillometer (vineyard) and in one position also latent heat flux, $L E$, was measured (vineyard). However, due to the pivot irrigation system at the corn field, the sensor had to be located at the edge of the corn field adjacent to the vineyard, meaning that the measurement either represented the vineyard or the corn, depending on wind direction. Net radiation and soil heat flux were measured only at four sites; the vineyard, forest nursery, corn and a wheat stubble field. For a location map one is referred to Fig. 1 in Van der Kwast et al. (2009) where also a land cover map is provided, showing the main land cover units.

Aerodynamic properties were assigned to the different land cover units using averaged field observations of canopy height, $h_{c}$ (Fernandez et al., 2005) in combination with the classical relations (Brutsaert, 1982) where surface roughness length for momentum transport, $z_{0 M}$, is taken equal to $1 / 8^{*} h_{C}$ and the displacement height, $d_{0}$, equal to $2 / 3^{*} h_{C}$. An exception was made for the roughness length of the corn fields, which were extremely dense, resulting in a much smoother surface. Therefore a roughness length value equal to that of the sunflower was assigned, which closely resembled estimates from turbulence measurements done over the maize (Timmermans et al., 2009). Moreover, the displacement heights of the wheat stubble and forest nursery land cover were chosen equal to zero, since these units were characterized by a very open and heterogeneous character.

\section{Results and discussion}

In this section we first present the quality and the differences in LAI and fCover estimations using the LUT inversion and the scaled NDVI approaches. Validation of the energy balance model output is then performed by means of the flux towers measurements. Differences in the flux components simulated with both canopy parameter retrieval methods are analyzed additionally in a spatial context. A general discussion on the applied method(s), their problems and applicability (in an operational context) concludes this section.

\subsection{Vegetation characteristics versus observations}

Retrieval performances of the LUT inversion and NDVI approaches were evaluated using LAI and fCover data from campaigns measurements (see Sect. 2.3.3). Crops not covered by the flux stations, such as sugar beet, garlic, potatoes and onion, were included in the analyses as well to test the general applicability of the models.

The comparison with the ground measured fCover data with both approaches (LUT inversion: "fCover lut"; NDVI approach: "fCover ${ }_{\text {ndvi }}$ ") resulted in a slightly higher accuracy of fCover lut, with Root Mean Squared Differences (RMSD) for fCover lut $_{\text {of }} 0.12$ and for fCover ${ }_{\text {ndvi }}$ of 0.15 . The 
plots in Fig. 2a, b give a graphical impression of the estimation quality, indicating a tendency of overestimation of the NDVI approach, especially at the higher values. Since TSEB has a greater sensitivity to fCover, in determining the turbulent fluxes, especially at high vegetation cover conditions (Timmermans et al., 2007) this is considered an important drawback of the NDVI approach.

In case of LAI (LUT inversion: "LAI lut"; NDVI approach: "LAI $\mathrm{ndvi}$ ") the LUT inversion approach provided clearly a higher retrieval accuracy in comparison with the ground data (Fig. 2c, d), with RMSD of 0.79 ( $\mathrm{LAI}_{\text {lut }}$ ) versus RMSD of $1.44\left(\mathrm{LAI}_{\text {ndvi }}\right)$. Also here the empirical model has a trend to overestimate the parameter. Clearly noticeable is also the well-known problem of saturation at higher LAI values ("plateau-effect"), illustrated by the scatter plot in Fig. 2c.

The overestimation of fCover using the scaled NDVI approach can be caused by an inaccurate $\mathrm{NDVI}_{\min }$ value, i.e. the value for bare soil reflectance, which in reality varies and is probably different (higher) when calculating the mean over all bare soil pixels in the scene (Montandon and Small, 2008). Soils have a variable NDVI due to the fact that the relative variation of the spectral signal in the visible red waveband region is larger than in the near infrared. Increasing soil water leads consequently to an augmentation of NDVI, generating for example a difference of NDVI of $10 \%$ between a wet and a dry soil background for a LAI of 1 (Bach and Verhoef, 2003). Differences of land cover and irrigation practise which influence the soil background will therefore also have an effect on fCover estimation accuracy.

The PROSAILH model overcomes this problem by taking into account the soil reflectance variation by means of the $\alpha_{\text {soil-factor. }}$

However, the model tends to slightly underestimate high LAI values for crops with strong leaf clumping, as it was the case for potatoes in the present growth stage. This behaviour results from the nonlinearity of the LAI-reflectance relationship, leading to saturation effects (Baret et al., 2007). On the other hand, even the measurements could cause an overestimation of LAI, since the LAI-2000 can not separate between photosynthetic and non-photosynthetic plant components. This may occur whenever the built-in assumption of randomly distributed plant elements holds true. Thus, nongreen elements (such as stems or senescent leaves) reduce the measured gap fractions.

A detailed interpretation of the retrieval performances for the specific crop types is not given, since the objective is to evaluate the overall applicability of the RTM model for canopy parameter estimations. Considering that the PROSAILH model simplifies the canopy as a turbid medium, of which none of the crops really corresponds to, the retrieval performance can be regarded as satisfying. The implementation of some a priori information from the field measurements can support accurate retrievals.
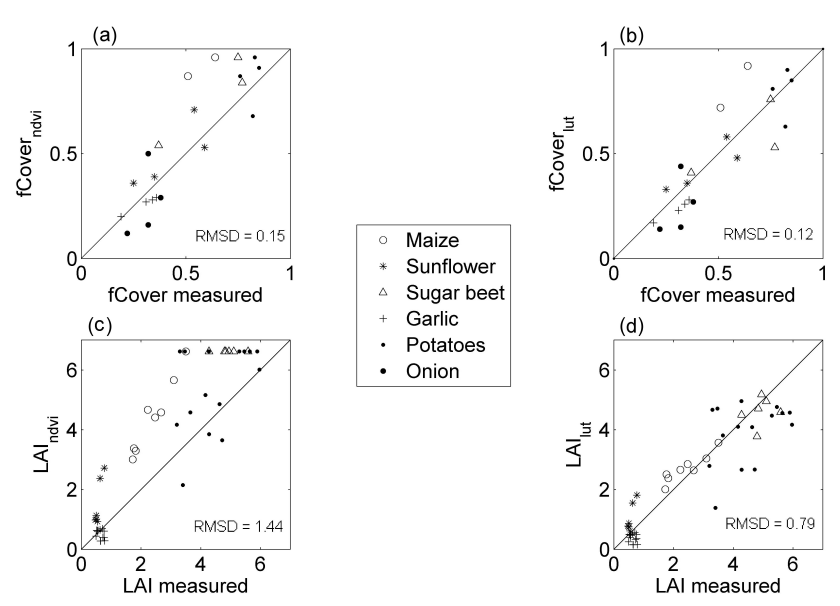

Fig. 2. Estimated versus measured fCover $(\mathbf{a}, \mathbf{b})$ and LAI values (c, d) using the scaled NDVI approach (a, c) and a LUT inversion approach based on PROSAILH model (b, d), for different crops monitored during the SPARC 2004 campaign.

\subsection{Water and heat fluxes}

Validation of the TSEB model output was performed in comparison with tower-based flux observations for the day of ASTER overpass. Model flux components were extracted from the image pixels in the vicinity of the flux towers, following a simple analytical footprint model, which is a reformulated version of Gash (1986). Details of the footprint model can be found in Timmermans et al. (2009).

The models are run on an area of almost $6 \times 6 \mathrm{~km}$ comprising $64 \times 64$ pixels around the Barrax vineyard which was the centre point of attention during the SPARC 2004 campaign (see also Fig. 1).

For all components, both TSEB runs (RTM inversion:

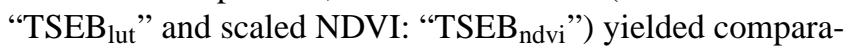
ble results versus observations and RMSD were in all cases lower than $50 \mathrm{~W} / \mathrm{m}^{2}$, which is considered acceptable. Net radiation yielded a RMSD of $46 \mathrm{~W} / \mathrm{m}^{2}$ versus observations for both approaches and gave almost identical results in all 4 sites (Fig. 3a). Also for the soil heat flux (Fig. 3b) and the sensible heat flux (Fig. 3c) output negligible differences between the NDVI and LUT approaches were seen. RMSD with observations for $G$ were 36 and $38 \mathrm{~W} / \mathrm{m}^{2}$ for the NDVI and LUT approaches, whereas for $H$ these were 43 and $42 \mathrm{~W} / \mathrm{m}^{2}$, respectively.

Although RMSD for $G$ and $H$ were almost equal for both $\mathrm{TSEB}_{\text {ndvi }}$ and $\mathrm{TSEB}_{\text {lut }}, \mathrm{TSEB}_{\text {lut }}$ appears to perform better at the lower values of $G$ and $H$. With the exception of the $G$ observation at the cut wheat site, all other sites showed similar performances for both $G$ and $H$. TSEB lut $_{\text {lut }}$ performing better at low values of $G$ and $H$ may indicate that the model performs better at sites that are characterized by high fCover, such as it is the case for the sunflower and maize fields. Therefore the model performance is discussed in a spatial context in the next section. 

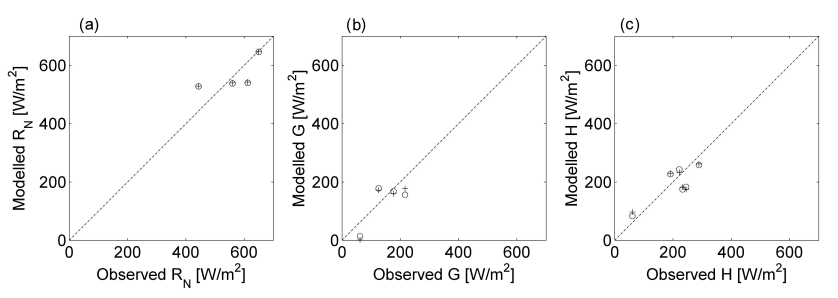

Fig. 3. Modelled versus observed fluxes of $R_{N}(\mathbf{a}), G(\mathbf{b})$ and $H(\mathbf{c})$, using the two approaches of canopy parameter estimations. Cross symbols represent the output from the scaled NDVI approach and the circles from LUT inversion.

\subsection{Spatial differences of flux modelling}

Differences between the two modelling approaches are shown in Fig. 4. Spatially distributed output for $R_{N}, G, H$ and $L E$ from TSEB $_{\text {ndvi }}$ are subtracted from output of TSEB $_{\text {lut }}$ $\left(\right.$ TSEB $_{\text {lut }}-$ TSEB $\left._{\text {ndvi }}\right)$.

The maps reflect what was noticed from observations at the flux tower sites; $R_{N}$ differences are negligible whereas $G$ estimates for $\mathrm{TSEB}_{\text {lut }}$ are higher than for $\mathrm{TSEB}_{\text {ndvi }}$ at high fCover, while $H$ (and to a lesser extent $L E$ ) shows lower fluxes for $\mathrm{TSEB}_{\text {lut }}$ in these areas, especially in the maize fields. The net radiation estimation seems rather insensitive to variations in LAI and fCover. This is understandable since LAI and fCover are only indirect inputs to the net radiation estimation, which is mainly driven by incoming solar radiation, and their effects basically act on the soil and canopy components. For example an increase in LAI will decrease the shortwave transmission which will increase the canopy net radiation but at the same time decrease the soil net radiation, see also Eqs. (4) and (5). As a result the net effect on the total net radiation is negligible. In order to consider the variations in the other energy balance components, that seem to originate from crop characteristics, the flux estimates will be analyzed in terms of land cover classes.

On the basis of a land cover map (Van der Kwast et al., 2009), simulated fluxes were extracted for all land uses. However, here we will focus on the five different land use classes covered by the stations (forest nursery, vineyard, sunflower, corn and wheat stubble), which enables us to assess the model accuracy to a certain extent. Since $R_{N}$ estimates are rather similar for both approaches we will focus on the remaining flux components from now on.

Figure 5 shows the spatial differences between $\mathrm{TSEB}_{\text {lut }}$ and TSEB $_{\text {ndvi }}$ calculated flux components, for every of the five land use classes and Fig. 6 the estimated fCover and LAI values for the respective classes.

Even though the estimation of $H$ and $G$ was almost identical for both model versions at the flux site at the forest nursery, the physical approach shows a trend of higher $H$ and lower $G$ fluxes when examining the entire class. Higher $H$ values theoretically might indicate more realistic results from
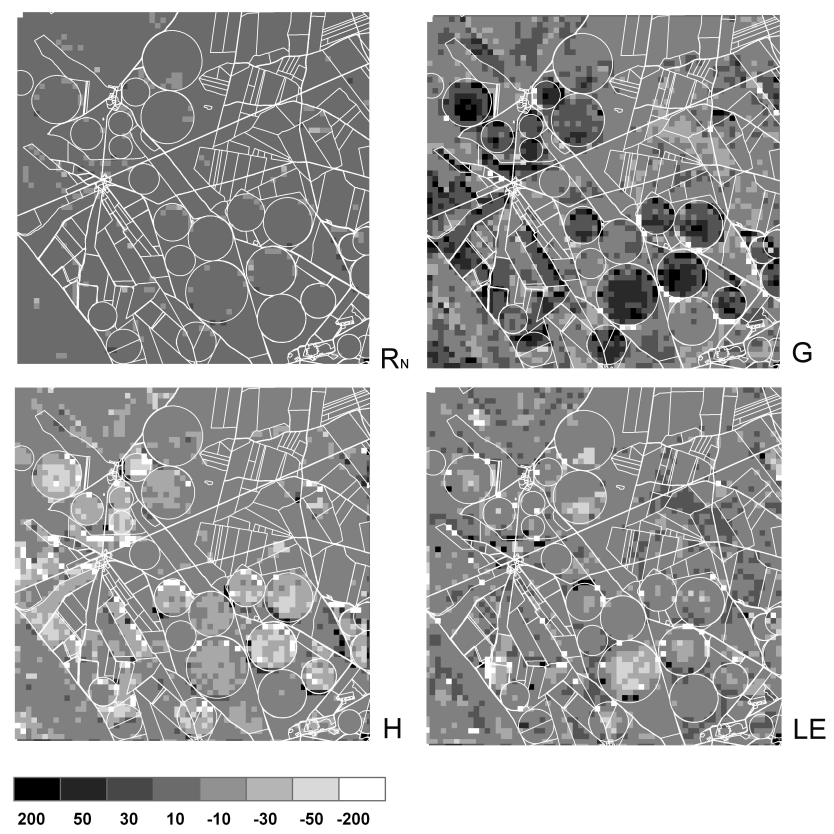

Fig. 4. Differences between TSEB output $R_{N}, G, H$ and $L E$ $\left(\mathrm{W} / \mathrm{m}^{2}\right)$, subtracting empirical approach of surface parameter estimations from the physical $\left(\mathrm{TSEB}_{\text {lut }}-\mathrm{TSEB}_{\text {ndvi }}\right)$, Barrax test site, 18 July 2004.

TSEB $_{\text {lut }}$, although uncertain as to how high, since this land use class is characterized by rather small green vegetation cover, low LAI values, but at the same time has rather large amounts of senescent grass cover. This would imply relatively high $H$ and relatively low $G$. To a certain extent this is also reflected in the higher estimates of fCover by the LUT approach. However, unfortunately there are no observations of fCover and LAI made over the forest nursery.

The vineyard case shows almost no differences between the two approaches, but the small number of pixels $(n=5)$ does not allow to draw significant conclusions.

Due to their planophile leaf orientation, sunflowers in early growth stages exhibit - with still relatively low LAI values $(\leq 2.7)$ - already high fCover (here up to 0.76 ). For this crop class the physical approach yielded also more realistic estimates of fCover (RMSD $=0.07$ for fCover lut $_{\text {lut }}$ and $\mathrm{RMSD}=0.11$ for fCover $_{\text {ndvi }}$ ). Since TSEB is sensitive to fCover with respect to $H$, the fluxes were probably modelled more accurate by $\mathrm{TSEB}_{\text {lut }}$ (as is shown for $H$ ). No measurements of $G$ and $R_{N}$ were available from this station, but the trend of higher $G$ from TSEB $_{\text {lut }}$ confirms the conclusion of lower fCover and LAI (visible in Fig. 6) being more realistic.

The land use class maize must be regarded as a special case. During the time of ASTER overpass, the dominating wind direction was west, causing the flux observation in this site to reflect the vineyard instead of the maize. This is confirmed by a high value for $H$, equal to $233 \mathrm{~W} / \mathrm{m}^{2}$, which appears far too high for an irrigated maize field with an fCover 

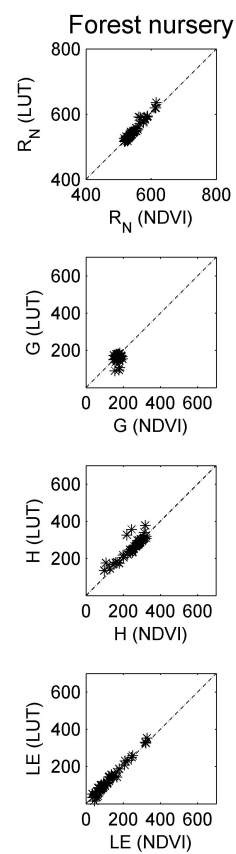
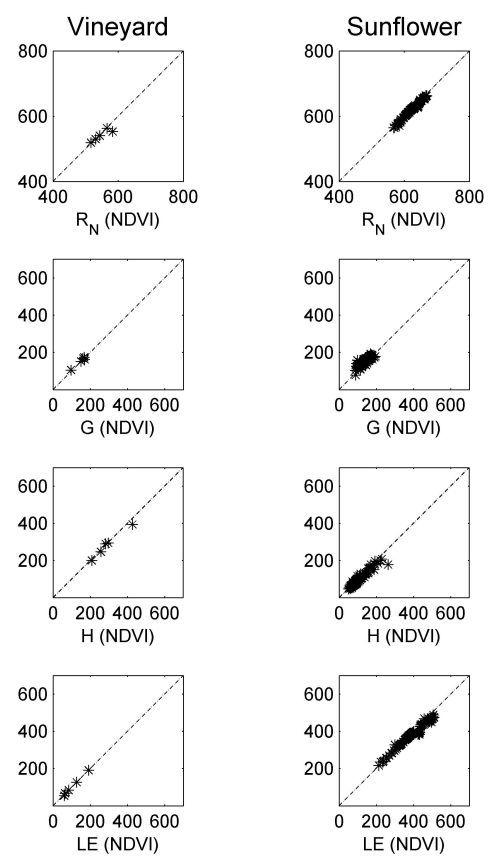
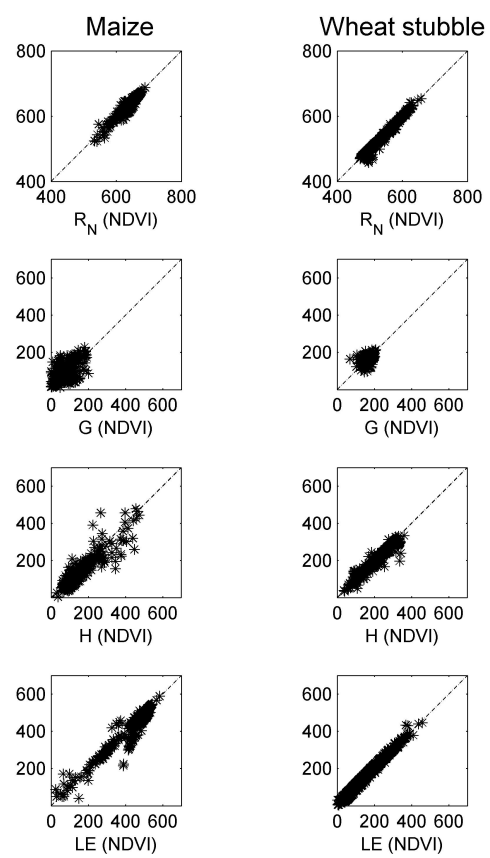

Fig. 5. Simulated fluxes of $R_{N}, G, H$ and $L E$ and by $\operatorname{TSEB}_{\text {ndvi }}$ versus $\mathrm{TSEB}_{\text {lut }}$ for different land use classes.
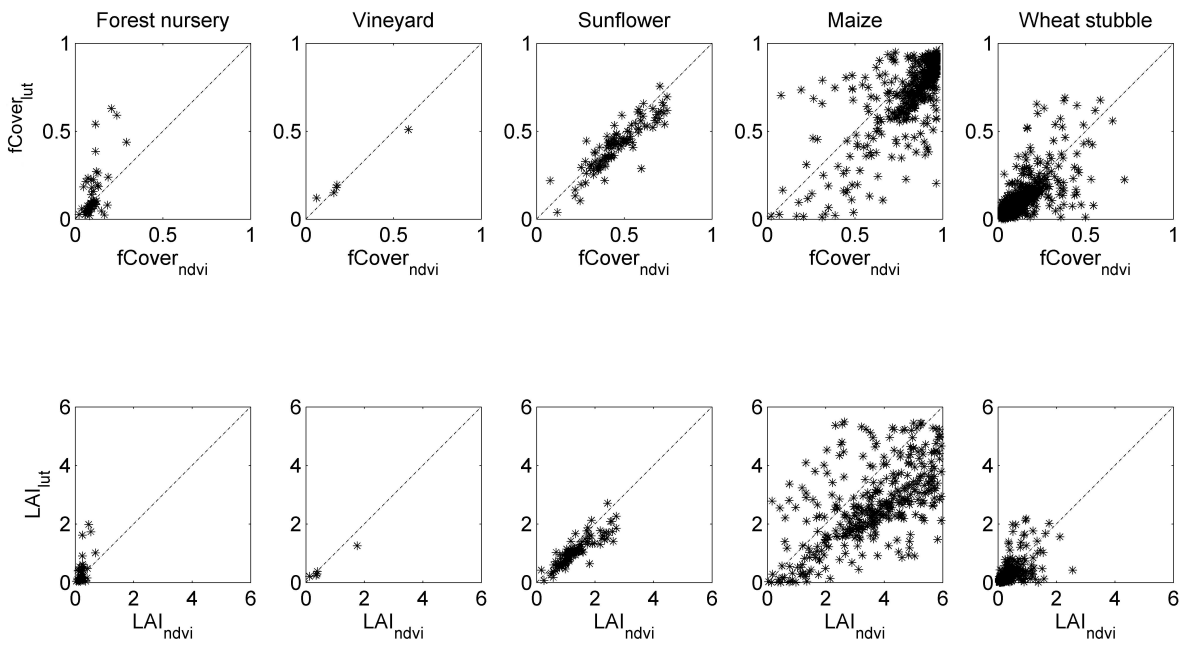

Fig. 6. Estimated values of fCover and LAI from scaled NDVI versus estimated by LUT inversion for the land use classes.

of 0.9 and LAI up to 6 . The estimation of LAI for maize was performed more accurate by the physical model (RMSD of 0.4 from $\mathrm{LAI}_{\text {lut }}$ against RMSD of 2.1 from $\mathrm{LAI}_{n d v i}$ ), as well as for fCover, even though only two measurements were available $\left(\mathrm{RMSD}=0.24\right.$ for fCover lut $_{\text {la }}$ and $\mathrm{RMSD}=0.34$ for fCover $_{\text {ndvi }}$ ).

The overestimation of LAI, and to a lesser extent fCover, by the $\mathrm{TSEB}_{\text {ndvi }}$ approach results in an underestimation of $G$ for this land use, also illustrated by the observation at this site, Fig. 3b. This effect is clearly visible for all maize-fields in Fig. 4b.
$\mathrm{TSEB}_{\text {lut }}$ estimates of $H$ for this land cover generally were lower than those from $\mathrm{TSEB}_{\text {ndvi }}$, where differences over the maize field next to the vineyard reached values up to $50 \mathrm{~W} / \mathrm{m}^{2}$, with $\mathrm{TSEB}_{\text {lut }}$ values around $75 \mathrm{~W} / \mathrm{m}^{2}$. These values resemble observations made over the maize during days preceding the ASTER overpass, when wind direction was coming from the maize (Timmermans et al., 2009). Therefore we feel that the $H$ fluxes are simulated more realistically by using the RTM based values of LAI and fCover as input. Differences for $L E$ estimates were variable within this land cover class, with a tendency of $\mathrm{TSEB}_{\text {lut }}$ yielding lower 
estimates. The differences seem to vary from field to field, which may originate from the irrigation scheme. The different estimation results of the two approaches may be caused by variations in soil reflectance due to (superficial) soil moisture differences, which are taken into account only by the physical model. This may also be an explanation for the fact that regarding the comparison of fluxes between $\mathrm{TSEB}_{\text {lut }}$ and TSEB $_{\text {ndvi }}$, maize exhibits the most pronounced differences of all land use classes, since some fields were fully irrigated and some neglected. The tendency of overestimating fCover with the NDVI approach seems to influence especially the $L E$ for a certain group of pixels, mainly over irrigated maize, resulting in differences ranging from 30 to $35 \mathrm{~W} / \mathrm{m}^{2}$.

In the last land use class, a wheat field shortly harvested, $\mathrm{TSEB}_{\text {lut }}$ resulted in a slightly better estimate of $H$, whereas $G$ was better estimated by TSEB $_{\text {ndvi }}$ at the flux observation site. When looking at the entire land cover class however, no distinct differences are seen for either one of the fluxes. Both $G$ and $H$ exhibit some scatter around the 1:1 line, which is also seen in the $L E$ flux but at a lesser extent. Although no measurements of LAI and fCover were made over this land use, it is characterized by rather low fCover $(<0.1)$ and LAI $(\leq 2)$. When looking at the scatter plots of Fig. 6 it is noticed that in the lower regions of LAI and fCover no clear distinction can be made between the NDVI and LUT approach, which is reflected in the scatter of the fluxes around the 1:1 line in Fig. 5 for this class.

Summarizing, $R_{N}$ shows for all land use classes the smallest variations between the two approaches. $G$ and $H$, and to a somewhat lesser extent $L E$, exhibit more pronounced differences, mainly over areas with high vegetation cover and high LAI. The LAI mainly influences the estimation of $G$, since an increase in LAI invokes a decrease in radiation received at the soil, whereas fCover mainly influences the turbulent fluxes through its effect on the component temperatures. This is of importance since the TSEB model is sensitive to fCover, when estimating turbulent fluxes, in particular at the high end as stated by Timmermans et al. (2007). This could be of interest for a wider range of crops or vegetation, because even for other crops with high fCover - not included in the measurements of flux towers - the physical approach yielded a slightly higher retrieval accuracy (see also Fig. 2) with sugar beet: RMSD (fCover $\left.{ }_{\text {lut }}\right)=0.14$ vs. RMSD $\left(\right.$ fCover $\left._{\text {ndvi }}\right)=0.16$ and potatoes: RMSD $\left(\right.$ fCover $\left._{l u t}\right)=0.10$ vs. RMSD $\left(\right.$ fCover $\left._{n d v i}\right)=0.11$. Even though flux observations were only available for a limited number of land covers, it is argued that the improved estimation of both LAI and fCover in general leads to slightly better flux estimates. However, further research is needed to demonstrate this effect also under a wider range of canopy characteristics.

Spatial differences between the TSEB lut $_{\text {and the }}$ TSEB $_{\text {ndvi }}$ model results were clearly related to land cover, with noticeable differences up to $50 \mathrm{~W} / \mathrm{m}^{2}$ for $H$ and $35 \mathrm{~W} / \mathrm{m}^{2}$ for $L E$ over irrigated crops and up to $20 \mathrm{~W} / \mathrm{m}^{2}$ for both the turbulent fluxes over dry areas. Although this may seem rather small, an instantaneous error of $35 \mathrm{~W} / \mathrm{m}^{2}$ could translate into $1.2 \mathrm{~mm}$ error in water use, which has considerable consequences for irrigation management.

\section{Conclusions}

In this study, the TSEB model was applied to the Barrax test site and evaluated with ground measurements from the SPARC campaign 2004. The inputs of leaf area index and fractional vegetation cover were estimated from CHRIS imagery by using the traditional scaled NDVI and a LUT inversion approach, based on the proposed bands of future ESA Sentinel-2 satellite. The LUT was constructed using the well established SAILH + PROSPECT radiative transfer model. The validation by means of a range of crops over the SPARC Barrax test site resulted in a better retrieval performance for the LUT approach. Differences in flux predictions in comparison with a limited number of station measurements were rather small. However, a differentiation between land use classes indicated a higher estimation quality of the physical approach, especially over areas that were characterized by higher LAI and higher fCover.

In view of operational applications, a physically based approach has several advantages over empirical methods. Differences in soil background due to soil moisture variations are taken into account by the RTM model and thus canopy parameters, such as LAI and fCover can be estimated more accurately. Moreover, the RTM based inversion does not (necessarily) require detailed in situ calibration data sets. This constitutes a major general advantage of physical over empirical models, rendering them more robust and generally applicable. The application of physically based models for estimating vegetation parameter as input for energy balance models is therefore recommended.

Acknowledgements. This work has been partly funded through ESA 18307/04/NL/FF. We would like to thank JuanCarlos Jimenez-Muñoz from the Global Change Unit of the University of Valencia for radiometric and atmospheric correction of the thermal ASTER data and Luis Guanter from GeoForschungsZentrum (GFZ) Potsdam, and his former Department of Thermodynamics of the University of Valencia, for preprocessing of CHRIS/Proba data.

Edited by: J. Wen

\section{References}

Anderson, M. C., Norman, J. M., Mecikalski, J. R., Otkin, J. A., and Kustas, W. P.: A climatological study of evapotranspiration and moisture stress across the continental U.S. based on thermal remote sensing. I. Model formulation, J. Geophys. Res,. 112, D11112, doi:10.1029/2006JD007506, 2007.

Atzberger, C.: Object-based retrieval of biophysical canopy variables using artificial neural nets and radiative transfer models, Remote Sens. Environ., 93, 53-67, 2004. 
Bach, H. and Verhoef, W.: Sensitivity studies on the effect of surface soil moisture on canopy reflectance using the radiative transfer model GeoSAIL, in proceedings of IGARSS 2003, 16791681, 2003.

Baret, F., Hagolle, O., Geiger, B., Bicheron, P., Miras, B., Huc, M., Berthelot, B., Nino, F., Weiss, M., Samain, O., Roujean, J. L., and Leroy, M.: LAI, fAPAR and fCover CYCLOPES global products derived from VEGETATION. Part 1: Principles of the algorithm, Remote Sens. Environ., 110, 275-286, 2007.

Bindlish, R., Kustas, W. P., French, A. N., Diak, G. R., and Mecikalski, J. R.: Influence of near-surface soil moisture on regional scale heat fluxes: model results using microwave remote sensing data from SGP97, IEEE T. Geosci. Remote, 39, 17191728, 2001.

Brutsaert W.: Evaporation into the atmosphere. Reidel, Dordrecht, The Netherlands, 299 pp., 1982.

Campbell, G. S. and Norman, J. M.: An introduction to Environmental Biophysics, Springer, New York ISBN 0-387-94937-2, 286 pp., 1998.

Chen, J. M., Rich, P. M., Gower, S. T., Norman, J. M., and Plummer, S.: Leaf area index of boreal forests: Theory, techniques and measurements, J. Geophys. Res.-Atmos., 102, 429-443, 1997.

Choudhury, B. J., Ahmed, N. U., Idso, S. B., Reginato, R. J., and Daughtry, C. S. T.: Relations between evaporation coefficients and vegetation indices studied by model simulations, Remote Sens. Environ., 50, 1-17, 1994.

Choudhury, B. J.: Relationships between vegetation indices, radiation absorption, and net photosynthesis evaluated by a sensitivity analysis, Remote Sens. Environ., 22, 209-233, 1987.

Combal, B., Baret, F., Weiss, M., Trubuil, A., Mace, D., Pragnère, A., Myneni, R., Y. Knyazikhin, Y., and Wang, L.: Retrieval of canopy biophysical variables from bidirectional reflectance using prior information to solve the ill-posed inverse problem, Remote Sens. Environ., 84, 1-15, 2003.

Darvishzadeh, R., Skidmore, A., Schlerf, M., and Atzberger, C.: Inversion of a radiative transfer model for estimating vegetation LAI and chlorophyll in a heterogeneous grassland, Remote Sens. Environ., 112, 2592-2604, 2008.

European Space Agency (ESA): GMES Sentinel-2 Mission Requirements Document, issue 2 revision 0-30/01/2007, EOPSM/1163/MR-dr, p. 31, 2007.

Fernandez, G., Moreno, J., Gandia, S., Martinez, B., Vuolo, F., and Morales, F.: Statistical variability of field measurements of biophysical parameters in SPARC-2003 and SPARC-2004 data campaigns, in: Proceedings of the SPARC Final Workshop WPP250, Enschede, The Netherlands, 4-5 July 2005, 2005.

French, A. N., Schmugge, T. J., Kustas, W. P., Brubaker, K. L., and Prueger, J.: Surface energy fluxes over El Reno, Oklahoma, using high-resolution remotely sensed data, Water Resour. Res., 39 (6), 1164, 2003.

Gash, J. H. C.: A note on estimating the effect of a limited fetch on micrometeorological evaporation measurements, Bound.-Lay. Meteorol., 35, 409-413, 1986.

Haboudane, D., Miller, J. R., Pattey, E., Zarco-Tejada, P. J., and Strachan, I. B.: Hyperspectral vegetation indices and novel algorithms for predicting green LAI of crop canopies: Modeling and validation in the context of precision agriculture, Remote Sens. Environ., 90, 337-352, 2004.

Jacquemoud, S. and Baret, F.: PROSPECT: A model of leaf optical properties spectra, Remote Sens. Environ., 34, 75-91, 1990.

Jimenez-Munoz, J. C. and Sobrino, J. A.: Feasibility of retrieving land-surface temperature from ASTER TIR bands using twochannel algorithms: a case study of agricultural areas, IEEE T. Geosci. Remote, 4, 60-64, 2007.

Kustas, W. P. and Norman, J. M.: Evaluation of soil and vegetation heat flux predictions using a simple two-source model with radiometric temperatures for partial canopy cover, Agr. Forest Meteorol., 94, 13-29, 1999.

Kustas, W. P., Norman, J. M., Schmugge, T. J., and Anderson, M. C.: Mapping surface energy fluxes with radiometric temperature, in: Thermal remote sensing in land surface processes, edited by: Quattrochi. D. A. and Luvall, J. C., Boca Raton, Florida, CRC Press, 205-253, 2004.

Kuusk, A.: The hot-spot effect in plant canopy reflectance, in: R.B. Myneni and J. Ross (Ed.), Photon -vegetation interactions, Springer-Verlag, New York, 139- 159, 1991.

Li, F., Kustas, W. P., Prueger, J. H., Neale, C. M. U., and Jackson, T. J.: Utility of remote sensing based two-source energy balance model under low and high vegetation cover conditions, J. Hydrometeorol., 6, 878-891, 2005.

Montandon, L. M. and Small, E. E.: The impact of soil reflectance on the quantification of the green vegetation fraction from NDVI, Remote Sens. Environ., 112(4), 1835-1845, 2008.

Moreno, J. and participants of the SPARC campaigns: The SPECTRA Barrax Campaign (SPARC): Overview and first results from CHRIS data, in: Proceeding of the 2nd CHRIS/Proba Workshop Frascati, Italy, ESA/ESRIN, 28-30 April, 2004.

Norman, J. M., Kustas, W. P., and Humes, K. S.: A two-source approach for estimating soil and vegetation energy fluxes in observations of directional radiometric surface temperature, Agr. Forest Meteorol., 77, 263-293, 1995.

Richter, K., Atzberger, C., Vuolo, F., Weihs, P., and D'Urso, G.: Experimental assessment of the Sentinel-2 band setting for RTMbased LAI retrieval of sugar beet and maize, Can. J. Remote Sens., in press, 2009.

Schmugge, T. J., Kustas, W. P., and Humes, K. S.: Monitoring land surface fluxes using ASTER observations, IEEE T. Geosci. Remote, 36, 1421-1430, 1998.

Sobrino, J. A., Jimenez-Munoz, J. C., Balick L., Gillespie, A. R., Sabol, D. A., and Gustafson W. T.: Accuracy of ASTER level2 thermal-infrared standard products of an agricultural area in Spain, Remote Sens. Environ., 106, 146-153, 2007.

SPARC data acquisition report, Contract no: 18307/04/NL/FF, University Valencia, 2004.

Stenberg, P., Rautiainen, M., Manninen, T., Voipio, P., and Smolander, H.: Reduced simple ratio better than NDVI for estimating LAI in Finnish pine and spruce stands, Silva Fenn., 38(1), 3-14, 2004.

Su, Z., Timmermans, W. J., Gieske, A. S. M., Jia, L., Elbers, J. A., Olioso, A., Timmermans, J., Van der Velde, R., Jin, X., Van der Kwast, H., Sabol, D., Sobrino, J. A., Moreno, J., and Bianchi, R.: Quantification of land-atmosphere exchanges of water, energy and carbon dioxide in space and time over the heterogeneous Barrax site, Int. J. Remote Sens., 29, 5215-5235, 2008.

Timmermans, W. J., Kustas, W. P., Anderson, M. C., and French, A. N.: An intercomparison of the Surface Energy Balance Algorithm for Land (SEBAL) and the Two-Source Energy Balance (TSEB) modeling schemes, Remote Sens. Environ., 108, 369- 
384, 2007.

Timmermans, W. J., Su, Z., and Olioso, A.: Footprint issues in scintillometry over heterogeneous landscapes, Hydrol. Earth Syst. Sci. Discuss., 6, 2099-2127, 2009,

http://www.hydrol-earth-syst-sci-discuss.net/6/2099/2009/.

van der Kwast, J., Timmermans, W., Gieske, A., Su, Z., Olioso, A., Jia, L., Elbers, J., Karssenberg, D., and de Jong, S.: Evaluation of the Surface Energy Balance System (SEBS) applied to ASTER imagery with flux-measurements at the SPARC 2004 site (Barrax, Spain), Hydrol. Earth Syst. Sci. Discuss., 6, 11651196, 2009,

http://www.hydrol-earth-syst-sci-discuss.net/6/1165/2009/.

Verhoef, W.: Light scattering by leaf layers with application to canopy reflectance modeling: the SAIL Model, Remote Sens. Environ., 16, 125-141, 1984.
Verhoef, W.: Earth observation modeling based on layer scattering matrices, Remote Sens. Environ., 17, 165-178, 1985.

Vuolo, F., Dini, L., and D'Urso, G.: Retrieval of Leaf Area Index from CHRIS/PROBA data: an analysis of the directional and spectral information content, Int. J. Remote Sens., 29(17), 5063-5072, 2008.

Weiss, M., Baret, F., Myneni, R. B., Pragnère, A., and Knyazikhin, Y.: Investigation of a model inversion technique to estimate canopy biophysical variables from spectral and directional reflectance data, Agronomie, 20, 3-22, 2000.

Zhan, X., Kustas, W. P., and Humes, K. S.: An intercomparison study on models of sensible heat flux over partial canopy surfaces with remotely sensed surface temperature, Remote Sens. Environ., 58, 242-256, 1996. 